Theories \& Applications, the International Edition

Printed Version : (ISSN 2090-5262)

Online Version : (ISSN 2090-5270)

November 2014, Volume 4, No. 3 Pages (158 - 169)

\title{
Management of Sports Facilities and its Effects on Preventing Security Implications.
}

\section{Dr. Mustafa Ahmed Abd El-Haleem}

Assistant professor, Curricula and Methodology Dept. Faculty of Physical Education - Tanta University, Egypt.

\begin{abstract}
The current research aims at evaluating the reality of managing sports facilities to prevent any security implications. The researcher used the descriptive approach. Research community includes (94) members. Main study was performed on (74) participants. The main tool is "Questionnaire for Sports Facility Management and its effects on Security Implications". In the light of this research results, the researcher designed a questionnaire for Sports facility management and its effects on security implications. The questionnaire in its final version included (31) items divided into three axes: the nature of sports facility structure from a security perspective (11 items) - safety measures in sports facilities (10 items) - nature of crowds' behaviors inside sports facilities (10 items). The researcher concluded that securing sports facilities prevent security implications. It is very important to identify the responsibilities of security guards in securing such facilities in addition to putting specific plans for such procedures. Securing facilities depends on specific rules and regulations according to the requirements and modern advances in facility structure. Procedures of securing facilities differ in unusual situations compared to regular procedures of regular situations. Some procedures are related to communication while others concern transportation. Finally, safety procedures depend on the efficiency of security guards in initiating these procedures. Therefore, security specialists should know well basics and rules of securing facilities in addition to risks concerning these procedures.
\end{abstract}

Key words: Sports Facility Management - Security Implication.

\section{Introduction}

$\mathrm{S}$ ports management is the key for every development and the core of every change as it us a continuous process that never stops. Therefore, all workers and professionals of sports management should make any additions or modifications that suit the process of sports management in addition to studying all situations and factors affecting them to choose the best of them according to trends and perspectives of reality and future of the sports movement.

Coalter (2007) indicated that governmental policies all over the world push towards more attention to sports facilities as a major type of investment in human capital. These policies are built upon the importance for executives in sports facilities on all levels (facility management - resources management - activities and competitions management services management - marketing) to enjoy specific efficiencies to initiate policies of quality concerning services introduced inside the facility for members or outside the facility for fans (7: 537-559).

Regulations for Managing and Running Sports Facilities at the Ministry of Youth and Sport (2007) indicated in article (1) that the sports facility is considered a managerial unit - a directorate - under the general bureau of Youth and Sport Governorate. It is under direct supervision of the Ministry Deputy and includes the main court, closed halls, swimming pools, open courts, sports medicine unit, youth accommodation or athletes' hotel established on the same area of the stadium in addition to any other projects attached to the stadium, either at the same area or in various areas all over the governorate. Article (4) indicates that facilities are divided as follows: main court - closed hall - swimming pool - youth accommodation - athletes' hotel - sports medicine unit - commercial shops - the gym - open courts any other facility (16: 1-9).

The researcher thinks that managing the facility prevents many problems that may appear in sports facilities. John Baldoi (2000) indicated that sometimes, facility management is not based on objective bases away from any personal interference or on scientific criteria. Instead, it is based on personal experience or on studying and analyzing suggestions and alternatives without any experience for choosing the best. This leads to inefficiency and ineffectiveness in decision making (13: 123).

According to his experience in the sports field, the researcher thinks that the lack of readiness of sports facility to host sports competitions in addition to any events caused by problems that affect security and stability with various degrees according to the severity and implications can result in riots and damage peace and public security inside the facility. These negative effects of security reflect on facility management. Volkamer (1996) indicates that psychological characteristics of the crowds during sports competitions are very important factors that lead to violence inside and outside terraces which in turn leads to riot and intolerance. Their behavior as a group is totally different from their behavior as individuals as their thoughts and feelings are 
unified in one direction. This is known as the collective mind (23: 92-94).

Tenenbaum \& Stewart (1997), Taylor \& Plumely (1998), Mattew (2003), Spiro et al (2005) and Stacey (2006) indicate that security implications in sport are due to several reasons including the lack of planning for public convenience, the lack of knowledge about crisis management, the lack of suitable training for police forces and civil protection, socio-economic problems of the crowds, marginal management problems in facility management like closed doors, improper entrances, poor designs of facilities, poor infrastructure of the facility and the lack of clear indicative signs in addition to other factors like crowds riot and over crowdedness (22) (21) (15) (19) (20).

Forsdic (1997), Decker (2001) and Stacey (2006) indicated that some security implications are due to role ambiguity of the administrative situation of securing the facility from inside, decrease of opportunities, risks of goal achievement, purposeful damage, media attacks and rumors. Sports disasters are affected by the improper structure of the sports facility, ignoring public values and audience trends. Therefore, sports disaster is identified as the appearance of a unexpected risky situation inside the facility due to actors concerning over crowdedness, crowds' rush, explosives, riots and players' follies (11) (9) (20).

The problem of this research is in identifying the reality of sports facilities management and its security reflections in addition to security implications that appeared in Egyptian sports courts after $25^{\text {th }}$ January revolution starting with riots of Ghazl Al-Mahalla vs. Al-Ahly match at Ghazl AlMahalla Stadium and Al-Zamalik vs. Al-Effriky Al-Tonisy match at Cairo Stadium where secure locations of stadiums helped decreasing its security implications and ending with Al-Masry vs. Al-Ahly match (the massacre or Port Said) as these events indicate the important role of facility management in preventing security implications.

Egypt is deeply concerned in supporting sports and improving and expanding this major sector to suit the international ranks of Egypt in most sports fields. This sector can achieve more but traditional methods of management are dated and not suitable for professional management of this promising sector of investment to bring more revenues.
Reviewing related literature like Gameel (2005), Zhang et al (2007), Finch et al (2009), Zhang et al (2009), Shamansouri \& Hashemi (2010), Huang et al (2011), Al-Owainy (2012) and Abu Al-Einin (2012), the researcher found out that none of these studies dealt with facility management and its effects on preventing security implications (5) (25) (10) (26) (18) (12) (4) (1).

This study is of particular importance as facility management and its effects on security implications is relatively new topic for study in addition to its vital importance for the current situation in Egypt. This topic is neglected in scientific research although its applied importance is very clear as it will improve the facility management and help facing any unexpected security implications. It will also help sustaining the feasibility of establishing sports facilities and improving services they provide.

The researcher thinks that the real situation of sports facilities in the light of current security implications is not suitable for its objectives of establishment in addition to crowds' behaviors that may lead to riots which in turn affect objectives of these facilities negatively.

Aim: The current research aims at evaluating the reality of managing sports facilities to prevent any security implications through identifying:

1. The nature of sports facility structure from a security perspective

2. Safety measures in sports facilities

3. Crowds' behaviors inside sports facilities

\section{Research Questions:}

1. What is the nature of sports facility structure from a security perspective?

2. What are the safety measures in sports facilities?

3. What is the nature of crowds' behaviors inside sports facilities?

\section{Methods:}

Approach: The researcher used the descriptive approach.

Participants: Research community includes all directors of sports facilities and their deputies in sports stadiums at Delta Governorates ( $n=7)$. Table (1) shows research community.

Table (1):

research Community

\begin{tabular}{|c|c|c|c|c|c|c|c|c|c|}
\hline Governorate & $\begin{array}{c}\text { Number of } \\
\text { facilities }\end{array}$ & Community & $\begin{array}{c}\text { Facilities } \\
\text { Director }\end{array}$ & $\begin{array}{c}\text { Closed } \\
\text { hall } \\
\text { director }\end{array}$ & $\begin{array}{c}\text { Gym } \\
\text { director }\end{array}$ & $\begin{array}{c}\text { Swimming } \\
\text { pool } \\
\text { director }\end{array}$ & $\begin{array}{c}\text { Main } \\
\text { court } \\
\text { director }\end{array}$ & $\begin{array}{c}\text { Sports } \\
\text { hospital } \\
\text { director }\end{array}$ & $\begin{array}{c}\text { Hotel } \\
\text { director }\end{array}$ \\
\hline Gharbia & 7 & 14 & 2 & 2 & 2 & 2 & 2 & 2 & 2 \\
\hline Kafr Al-Shaikh & 7 & 14 & 2 & 2 & 2 & 2 & 2 & 2 & 2 \\
\hline Daquahlia & 7 & 14 & 2 & 2 & 2 & 2 & 2 & 2 & 2 \\
\hline Bohaira & 5 & 10 & 2 & 2 & 2 & 0 & 2 & 2 & 0 \\
\hline Damietta & 7 & 14 & 2 & 2 & 2 & 2 & 2 & 2 & 2 \\
\hline Sharquia & 7 & 14 & 2 & 2 & 2 & 2 & 2 & 2 & 2 \\
\hline
\end{tabular}




\begin{tabular}{|c|c|c|c|c|c|c|c|c|c|}
\hline Governorate & $\begin{array}{c}\text { Number of } \\
\text { facilities }\end{array}$ & Community & $\begin{array}{c}\text { Facilities } \\
\text { Director }\end{array}$ & $\begin{array}{c}\text { Closed } \\
\text { hall } \\
\text { director }\end{array}$ & $\begin{array}{l}\text { Gym } \\
\text { director }\end{array}$ & $\begin{array}{c}\text { Swimming } \\
\text { pool } \\
\text { director } \\
\end{array}$ & $\begin{array}{c}\text { Main } \\
\text { court } \\
\text { director }\end{array}$ & $\begin{array}{c}\text { Sports } \\
\text { hospital } \\
\text { director } \\
\end{array}$ & $\begin{array}{c}\text { Hotel } \\
\text { director }\end{array}$ \\
\hline Minofia & 7 & 14 & 2 & 2 & 2 & 2 & 2 & 2 & 2 \\
\hline Total & 47 & 94 & 14 & 14 & 14 & 12 & 14 & 14 & 12 \\
\hline
\end{tabular}

Table (1) indicates that research community includes (94) members. Main study was performed on (74) participants while (20) were used as a pilot sample for calculating validity and reliability of the questionnaire.

\section{Data Collection Tool:}

The main tool is "Questionnaire for Sports Facility Management and its effects on Security Implications". To design the questionnaire, the researcher followed the following steps:

1. Review of related literature.

2. Review of questionnaires for managing sports facilities like Gameel (2005), Zhang et al (2007), Finch et al (2009), Zhang et al (2009), Shamansouri \& Hashemi (2010), Huang et al (2011), Al-Owainy (2012) and Abu Al-Einin (2012). (5) (25) (10) (26) (18) (12) (4) (1).

3. Identifying main axes of the questionnaire ( 3 axes) and presenting them to experts (preliminary version)

4. Reaching final version of axes

5. Formulating items for each axis (preliminary version)

6. Presenting items of each axis to experts of sports administration and sports facility management

7. Omitting items according to experts' opinions

8. Reaching the final version of the questionnaire. Questionnaire Validity :To establish questionnaire validity, the researcher used jurors' validity and internal consistency methods.

Jurors'validity: The researcher presented the questionnaire to experts (11 staff members of faculties of physical education who are specialized in sports administration and sports facility management) from $6 / 1 / 2013$ to $23 / 1 / 2013$ to validate axes and items of the questionnaire. Tables (2), (3) and (4) show this process.

Table (2):

frequency, percentage, relative importance and relative weight of each axis of the Questionnaire for Sports Facility Management and its effects on Security Implications according to experts' opinions ( $\mathrm{n}=11)$

\begin{tabular}{|c|c|c|c|c|c|c|}
\hline \multirow{2}{*}{ Axis } & \multicolumn{2}{|c|}{ Agree } & \multicolumn{2}{|c|}{ Disagree } & \multirow{2}{*}{$\begin{array}{c}\text { Relative } \\
\text { weight }\end{array}$} & \multirow{2}{*}{$\begin{array}{c}\text { Relative } \\
\text { importance }\end{array}$} \\
\cline { 2 - 7 } & $\mathrm{F}$ & $\%$ & $\mathrm{~F}$ & $\%$ & 9 & 81.82 \\
\hline First axis: nature of sports facility structure from a security perspective & 9 & 81.82 & 2 & 18.18 & 9 \\
\hline Second axis: safety measures in sports facilities & 11 & 100 & 0 & 0 & 11 & 100 \\
\hline Third axis: nature of crowds' behaviors inside sports facilities & 10 & 90.91 & 1 & 9.09 & 10 & 90.91 \\
\hline
\end{tabular}

Table (2) indicated that relative importance of axes ranged between $81.82 \%$ and $100 \%$. The researcher included all axes reaching over $80 \%$ of relative importance.

Table (3):

percentages of agreement among experts on items of Questionnaire for Sports

Facility Management and its effects on Security Implications $\quad(n=11)$

\begin{tabular}{|c|c|c|c|c|c|}
\hline \multicolumn{2}{|c|}{ First Axis } & \multicolumn{2}{c|}{ Second Axis } & \multicolumn{2}{c|}{ Third Axis } \\
\hline Item & Agreement percentage (\%) & Item & Agreement percentage (\%) & Item & Agreement percentage (\%) \\
\hline 1 & 100 & 1 & 90.91 & 1 & 100 \\
\hline 2 & 81.82 & 2 & 100 & 2 & 63.64 \\
\hline 3 & 90.91 & 3 & 100 & 3 & 63.64 \\
\hline 4 & 100 & 4 & 81.82 & 4 & 54.55 \\
\hline 5 & 81.82 & 5 & 100 & 5 & 72.73 \\
\hline 6 & 100 & 6 & 100 & 6 & 100 \\
\hline 7 & 100 & 7 & 100 & 7 & 81.82 \\
\hline 8 & 100 & 9 & 90.91 & 8 & 100 \\
\hline 9 & 63.64 & 10 & 81.82 & 9 & 100 \\
\hline 10 & 100 & 11 & 54.55 & 10 & 100 \\
\hline 11 & 36.36 & 36.36 & 11 & 90.91 \\
\hline
\end{tabular}




\begin{tabular}{|c|c|c|c|c|c|}
\hline \multicolumn{2}{|c|}{ First Axis } & \multicolumn{2}{c|}{ Second Axis } & \multicolumn{2}{c|}{ Third Axis } \\
\hline Item & Agreement percentage (\%) & Item & Agreement percentage (\%) & Item & Agreement percentage (\%) \\
\hline 12 & 100 & 12 & 36.36 & 12 & 81.82 \\
\hline 13 & 90.91 & 13 & 81.82 & 13 & 100 \\
\hline 14 & & 14 & 36.36 & & \\
\hline
\end{tabular}

Table (3) indicated that agreement percentages among experts ranged between (36.36\%) and (100\%). The researcher included all items reaching $(70 \%)$ or higher and omitted the rest according to experts' opinions.

Table (4):

preliminary and final number of items of Questionnaire for Sports Facility Management and its effects on Security Implications

\begin{tabular}{|c|c|c|c|c|}
\hline Axis & Preliminary number & $\begin{array}{l}\text { Excluded } \\
\text { items }\end{array}$ & $\begin{array}{c}\text { Numbers of } \\
\text { excluded items }\end{array}$ & $\begin{array}{c}\text { Final } \\
\text { number }\end{array}$ \\
\hline First axis: nature of sports facility structure from a security perspective & 13 & 2 & 9,11 & 11 \\
\hline Second axis: safety measures in sports facilities & 14 & 4 & $10,11,12,14$ & 10 \\
\hline Third axis: nature of crowds' behaviors inside sports facilities & 13 & 3 & $2,3,4$ & 10 \\
\hline Total & 40 & 9 & & 31 \\
\hline
\end{tabular}

Table (4) indicates that preliminary number of items was research community and outside the main sample to (40) while (9) items were excluded from the questionnaire. calculate correlation coefficients between each item and its Final number of items is (31).

\section{Internal consistency:}

To calculate internal consistency, the researcher applied the questionnaire to a pilot sample $(n=20)$ from the same axis, each item and total score of questionnaire and each axis and total score of the questionnaire. This procedure was performed from $18 / 2 / 2013$ to $25 / 2 / 2013$ as shown in tables (5) and (6).

Table (5):

correlation coefficients $(\mathrm{R})$ between each item and its axis and each item and total score of questionnaire

$(n=20)$

\begin{tabular}{|c|c|c|c|c|c|c|c|c|}
\hline \multicolumn{3}{|c|}{ First axis } & \multicolumn{3}{|c|}{ Second axis } & \multicolumn{3}{|c|}{ Third axis } \\
\hline Item & Item/axis & Item/total & Item & Item/axis & Item/total & Item & Item/axis & Item/total \\
\hline 1 & 0.88 & 0.92 & 1 & 0.84 & 0.89 & 1 & 0.84 & 0.88 \\
\hline 2 & 0.83 & 0.87 & 2 & 0.86 & 0.91 & 2 & 0.92 & 0.87 \\
\hline 3 & 0.87 & 0.92 & 3 & 0.91 & 0.87 & 3 & 0.89 & 0.85 \\
\hline 4 & 0.73 & 0.77 & 4 & 0.92 & 0.86 & 4 & 0.79 & 0.83 \\
\hline 5 & 0.76 & 0.84 & 5 & 0.92 & 0.87 & 5 & 0.84 & 0.88 \\
\hline 6 & 0.88 & 0.92 & 6 & 0.88 & 0.84 & 6 & 0.73 & 0.79 \\
\hline 7 & 0.93 & 0.91 & 7 & 0.81 & 0.84 & 7 & 0.76 & 0.82 \\
\hline 8 & 0.89 & 0.86 & 8 & 0.93 & 0.86 & 8 & 0.88 & 0.92 \\
\hline 9 & 0.92 & 0.88 & 9 & 0.9 & 0.93 & 9 & 0.89 & 0.93 \\
\hline 10 & 0.84 & 0.87 & 10 & 0.84 & 0.89 & 10 & 0.86 & 0.92 \\
\hline 11 & 0.86 & 0.81 & & & & & & \\
\hline
\end{tabular}

$R$ table value on $P \leq 0.05=0.44$

Table (5) indicates statistically significant correlation between each item and its axis and each item and total score of questionnaire on $\mathrm{P} \leq 0.05$ that ranged between (-0.73) and (0.93). This indicates the questionnaire validity.

Table (6):

correlation coefficients between each axis and total score of the questionnaire $(n=20)$

\begin{tabular}{|c|c|}
\hline Axis & Correlation coefficient \\
\hline First axis: the nature of sports facility structure from a security perspective & 0.85 \\
\hline Second axis: safety measures in sports facilities & 0.86 \\
\hline Third axis: nature of crowds' behaviors inside sports facilities & $\mathbf{0 . 9 0}$ \\
\hline
\end{tabular}

\section{$R$ table value on $P \leq 0.05=0.44$}

Table (6) indicates statistically significant correlation between each axis and total score of questionnaire on $\mathrm{P} \leq 0.05$.

\section{Questionnaire Reliability:}

To calculate questionnaire reliability, the researcher used test/re-test procedure on a pilot sample $(n=20)$ from the 
same research community and outside the main sample. This procedure was applied from $2 / 3 / 2013$ to $17 / 3 / 2013$ with (15) days interval between test and retest. Table (7) shows reliability of each axis.

Table (7):

correlation coefficients between test and rests of the questionnaire $(n=20)$

\begin{tabular}{|c|c|c|c|c|c|}
\hline \multicolumn{2}{|c|}{ First axis } & \multicolumn{2}{|c|}{ Second axis } & \multicolumn{2}{|c|}{ Third axis } \\
\hline Item & $\mathrm{R}$ & Item & $\mathrm{R}$ & Item & $\mathrm{R}$ \\
\hline 1 & 0.85 & 1 & 0.88 & 1 & 0.84 \\
\hline 2 & 0.87 & 2 & 0.86 & 2 & 0.9 \\
\hline 3 & 0.84 & 3 & 0.79 & 3 & 0.91 \\
\hline 4 & 0.86 & 4 & 0.91 & 4 & 0.85 \\
\hline 5 & 0.9 & 5 & 0.88 & 5 & 0.86 \\
\hline 6 & 0.88 & 6 & 0.92 & 6 & 0.84 \\
\hline 7 & 0.92 & 7 & 0.86 & 7 & 0.92 \\
\hline 8 & 0.84 & 8 & 0.84 & 8 & 0.84 \\
\hline 9 & 0.85 & 9 & 0.92 & 9 & 0.9 \\
\hline 10 & 0.91 & 10 & 0.87 & 10 & 0.88 \\
\hline 11 & 0.83 & & & & \\
\hline
\end{tabular}

\section{$R$ table value on $P \leq 0.05=0.44$}

Table (7) indicates statistically significant correlation between test and retest on $\mathrm{P} \leq 0.05$. This correlation ranged between (-0.79) and (0.92). This indicates questionnaire reliability.

\section{Main Application:}

Main application was performed on a main sample $(n=74)$ from $23 / 3 / 2013$ to $29 / 4 / 2013$. The questionnaire included (31) items and application was done according to the following steps:

- Fields visits to stadiums under investigation $(n=7)$

- Applying the questionnaire to the research sample $(n=74)$

Data Analysis:

Table (8):

Sample opinions about the first axis: the nature of sports facility structure from a security perspective

$(n=74)$
After main application, the researcher recorded data on data $\operatorname{logs}$ according to the correction key (available $=3$ points somehow available $=2$ points - not available $=1$ point $)$.

Statistical treatment:

The researcher used SPSS software to calculate the following:

$\begin{array}{llll}- & \text { Percentages } & - & \text { Relative weight } \\ - & \text { Relative } & - & \text { Correlation } \\ \text { importance } & & \text { coefficient } \\ \text { - Internal } & \text { consistency } & & \text { Reliability } \\ \text { (test/retest) }\end{array}$

$-\mathrm{CHI}^{2}$

\begin{tabular}{|c|c|c|c|c|c|c|c|c|c|}
\hline \multirow{2}{*}{ Item } & \multicolumn{2}{|c|}{ Available } & \multicolumn{2}{|c|}{ Somehow available } & \multicolumn{2}{|c|}{ Not available } & \multirow{2}{*}{ Relative weight } & \multirow{2}{*}{ Relative importance } & \multirow{2}{*}{$\mathrm{CHI}^{2}$} \\
\hline & $\mathrm{F}$ & $\%$ & $\mathrm{~F}$ & $\%$ & $\mathrm{~F}$ & $\%$ & & & \\
\hline 1 & 3 & 4.05 & 41 & 55.41 & 30 & 40.54 & 121 & 54.5 & 31 \\
\hline 2 & 1 & 1.35 & 29 & 39.19 & 44 & 59.46 & 105 & 47.3 & 38.62 \\
\hline 3 & 31 & 41.89 & 27 & 36.49 & 16 & 21.62 & 163 & 73.42 & 4.89 \\
\hline 4 & 39 & 52.7 & 25 & 33.78 & 10 & 13.51 & 177 & 79.73 & 17.05 \\
\hline 5 & 17 & 22.97 & 31 & 41.89 & 26 & 35.14 & 139 & 62.61 & 4.08 \\
\hline 6 & 1 & 1.35 & 29 & 39.19 & 44 & 59.46 & 105 & 47.3 & 38.62 \\
\hline 7 & 7 & 9.46 & 37 & 50 & 30 & 40.54 & 125 & 56.31 & 19.97 \\
\hline 8 & 41 & 55.41 & 23 & 31.08 & 10 & 13.51 & 179 & 80.63 & 19.65 \\
\hline 9 & 21 & 28.38 & 29 & 39.19 & 24 & 32.43 & 145 & 65.32 & 1.32 \\
\hline 10 & 53 & 71.62 & 11 & 14.86 & 10 & 13.51 & 191 & 86.04 & 48.83 \\
\hline 11 & 31 & 41.89 & 27 & 36.49 & 16 & 21.62 & 163 & 73.42 & 4.89 \\
\hline
\end{tabular}

\section{$\mathrm{CHI}^{2}$ on $\mathrm{P} \leq \mathbf{0 . 0 5}=\mathbf{5 . 9 9}$}

Table (8) shows frequencies, percentages, relative weight, relative importance and $\mathrm{CHI}^{2}$ of sample opinions about the first axis: the nature of sports facility structure from a security perspective. $\mathrm{CHI}^{2}$ calculated values were higher than its table value (5.99) for all items of this axis except for (3, 5, 9 and 11). $\mathrm{CHI}^{2}$ values ranged between (48.38) and 
(3 and 11). The most important item was (10) stating that "there are alternative power supplies to be used in emergencies". Its relative importance was $(86.04 \%)$. This indicates that sports facilities have alternative power supplies to be used in cases of unexpected blackout, especially for night events as this prevents robbery, targeted violence and violent attacks against specific persons in addition to decreasing police boredom for protecting audience, players, officials, assistants and other public figures. Item (8) indicates that "there is a first-aid unit with an ambulance in the facility" and its relative importance was $(80.63 \%)$. This indicates the importance of first-aid units equipped with ambulances as in some cases, athletes may need to be transferred quickly to the nearest hospital. Item (4) has a relative importance of $(79.73 \%)$ and indicates that "roads leading to the facility are easily controlled at its terminals". This indicates the importance of establishing these facilities outside city borders so that roads leading to these facilities can be secured and controlled easily. Item (3) has a relative importance of $(73.42 \%)$ and indicates that "sports facilities should be far from heavy traffic". This item was not statistically significant as most sports facilities, until very recently, were established on city edges but are now surrounded by more residence blocks in addition to the traffic crisis that is becoming worse especially during rush hours although roads are under development and expansion. Item (11) has a relative importance of $(73.42 \%)$ and indicates that "there should be signs for services provided for audience. This item was not statistically significant as sports facilities lack service criteria like signs that direct audience to emergency exits and other services as this helps crowd flow inside the facility.

There are statistically significant differences in favor of those who answered (somehow available) for items ( 1 and 7) as $\mathrm{CHI}^{2}$ values were higher than its table value except for items (5 and 9). The most important item was (9) stating that "there are extra emergency exits" with a relative importance of $(65.32 \%)$. This item was not statistically significant as there were no extra emergency exits although it is very important for mass crowds in cases of emergency. The researcher thinks that every stair or every part of the facility should include at least two exits with different directions of paths and free of any obstacles. Roofs of these paths should be made of non-flammable materials. Item (5) indicates that "there should be enough space for audience coming in and out of the facility" with a relative importance of (62.61\%). This item was not statistically significant and this indicates the importance of providing facilities with exits suitable for mass crowds. Item (7) indicates that "all doors should open from inside or outside as needed to avoid over crowdedness". Its relative importance was $(56.31 \%)$. This indicates that doors do not match with sports facilities standards as doors are designed to be used from inside or outside, especially during emergencies and crisis. Item (1) indicates that "sports facilities should fulfill security standards to secure human and material capabilities". Its relative importance was $(54.5 \%)$. This indicates that sports facilities are not capable of facing security implications, especially human risks including riots, violence, sabotage, hostile cheers and terrorist acts as sports events may provide such events with success factors (audience - media). General riot may arise due to intolerance, crowds' stimulation through media, officials' mistakes, police lack of politeness or even using events from one group or another due to economic, political or social circumstances. Such events are characterized by mass numbers of audience. It bears risks of sabotage towards the facility itself or cars and special equipment or violent acts against audiences or members involved in such events (players - Refereesassistants).

There are statistically significant differences in favor of those who answered (not available) as $\mathrm{CHI}^{2}$ values were higher than its table value except for items (2 and 6). The most important item was (2) stating that "sports facilities should be outside the residence belt" with a relative importance of $(47.30 \%)$. This indicates that most sports facilities are now near overcrowded residencies and if roads leading to these facilities were not wide enough, various disasters would become inevitable and most events would become impossible to initiate. Item (6) indicates that "courts' doors should be wide enough according to numbers of beneficiaries". Its relative importance was (47.3\%). This indicates that additional doors are needed according to facility size and its audience. It should include pathways, evacuation exits, staircases and barriers. Exits should be fire-proof and smoke-proof and provided with a vertical bar for opening. These doors should open to the outside. Emergency exits should be suitable in numbers and distribution across the facility, in addition to sufficient light and signs to indicate its directions.

Gameel (2005) (4) indicated that crisis of sports facilities and building and disasters of violence and riots are very serious and represent security threats inside and outside sports courts as they urge some athletes to riot in some youth centers. Zhang et al (2007) (25) indicated that over crowdedness is a major cause of stadiums disasters as security standards are not fulfilled in exits. In addition, the most important factors to avoid disasters are the quickness of evacuating audience. Finch et al (2009) (10) classified the factors affecting security measures of multi-use recreational facilities to include demographic variables (related to increased populations) and security variables. Therefore, security should be improved to insure secured exits consistent with safety measures. Zhang et al (2009) (26) indicated that designs based on performance are more inclusive in preventing random exit disasters in sports stadiums. These designs are more flexible than traditional designs in providing major buildings with safety measures. Huang et al (2011) (12) indicated that establishment standards are specific to each area (urban/rural) and should fulfill the needs of audience. These standards should include: establishing a facility system related to these standards and considering the quality of facilities, audience and numbers of beneficiaries. 
The researcher thinks that governmental organizations (ministries - governorates - local authorities ... etc.) should pay more attention to sports facilities including human and financial aspects in addition to bearing all costs of establishing a quality system for services provided to audience through these facilities. It is necessary to study recent factors affecting these facilities like urban sprawl, traffic, roads and other factors representing risks and

Table (9) Sample opinions about the second axis: safety measures in sports facilities $(n=74)$

\begin{tabular}{|c|c|c|c|c|c|c|c|c|c|}
\hline \multirow{2}{*}{ Item } & \multicolumn{2}{|c|}{ Available } & \multicolumn{2}{|c|}{ Somehow available } & \multicolumn{2}{|c|}{ Not available } & \multirow{2}{*}{ Relative weight } & \multirow{2}{*}{ Relative importance } & \multirow{2}{*}{$\mathrm{CHI}^{2}$} \\
\hline & $\mathrm{F}$ & $\%$ & $\mathrm{~F}$ & $\%$ & $\mathrm{~F}$ & $\%$ & & & \\
\hline 1 & 17 & 22.97 & 43 & 58.11 & 14 & 18.92 & 151 & 68.02 & 20.62 \\
\hline 2 & 22 & 29.73 & 32 & 43.24 & 20 & 27.03 & 150 & 67.57 & 3.35 \\
\hline 3 & 28 & 37.84 & 26 & 35.14 & 20 & 27.03 & 156 & 70.27 & 1.41 \\
\hline 4 & 6 & 8.11 & 27 & 36.49 & 41 & 55.41 & 113 & 50.9 & 25.16 \\
\hline 5 & 9 & 12.16 & 41 & 55.41 & 24 & 32.43 & 133 & 59.91 & 20.78 \\
\hline 6 & 31 & 41.89 & 30 & 40.54 & 13 & 17.57 & 166 & 74.77 & 8.3 \\
\hline 7 & 29 & 39.19 & 22 & 29.73 & 23 & 31.08 & 154 & 69.37 & 1.16 \\
\hline 8 & 7 & 9.46 & 21 & 28.38 & 46 & 62.16 & 109 & 49.1 & 31.64 \\
\hline 9 & 9 & 12.16 & 23 & 31.08 & 42 & 56.76 & 115 & 51.8 & 22.24 \\
\hline 10 & 6 & 8.11 & 18 & 24.32 & 50 & 67.57 & 104 & 46.85 & 41.94 \\
\hline
\end{tabular}

\section{$\mathrm{CHI}^{2}$ on $\mathrm{P} \leq 0.05=5.99$}

Table (9) shows frequencies, percentages, relative weight, relative importance and $\mathrm{CHI}^{2}$ of sample opinions about the second axis: safety measures in sports facilities. $\mathrm{CHI}^{2}$ calculated values were higher than its table value (5.99) for all items of this axis except for (2, 3 and 7). $\mathrm{CHI}^{2}$ values ranged between (41.94) and (1.16). Relative importance ranged between $(74.77 \%$ ) (Highest value for item 6) and (46.85\%) (Lowest value for item 10).

There are statistically significant differences in favor of those who answered (available) for item (6) as $\mathrm{CHI}^{2}$ values were higher than its table value except for items (3 and 7). The most important item was (6) stating that "each team's fans should sit in separate places" with a relative importance of $(74.77 \%)$. The researcher thinks that this factor is very important for safety measures and preventing security implications as separating fans will prevent intolerant behaviors. Item (3) indicates that "information about security services and safety measures inside the facility should be available for audience". Its relative importance was $(70.27 \%)$. This item was not statistically significant and thus indicates the lack of clear security vision to deal with audience through providing them with information about security services and safety measures inside the facility although this type of information prevents security implications. Item (7) indicates that "entrances and exits should be specified for audience according to capacity of terraces". Its relative importance was $(69.37 \%)$. This item was not statistically significant and thus indicates that it is important to specify entrances and exits according to capacity of terraces to avoid over crowdedness and to apply safety measures. compromising security of these facilities and its attendants. When establishing new facilities several standards should be considered including suitability of design to purpose of establishment, facility safety measures, entrances and exits, capacity of terraces, signs directing audience all over the facility and other factors. This indicates the effect of facility nature of structure on security implications.
Zhang et al (2007) indicates that the most important reasons of stadiums disasters are rush of crowds while leaving terraces as exits do not fulfill safety measures. Quickness of evacuation is a main cause for preventing such disasters. The authors designed some exit gates for courts of 2008 Olympic Games in China and this model was highly reliable and effective in decreasing over crowdedness (25: 26302636).

There are statistically significant differences in favor of those who answered (somehow available) for items (1,2 and 5) as $\mathrm{CHI}^{2}$ values were higher than its table value except for item (2). The most important item was item (1) stating that "there are alarm sets according to safety measures" and its relative importance was $(68.02 \%)$. This indicates that sports facilities need to follow safety measures to prevent fire incidences through a fire-alarm system that works automatically in cases of fire incidences without any human interference. This system should cover all parts of the facility as some incidences may occur deliberately through fireworks set by audience or even they may occur due to failure of power supplies network. Item (2) indicates that "Funds should be available for applying maximum safety measures in sports facilities". Its relative importance was $(67.57 \%)$. This item was not statistically significant as funds for applying maximum safety measures in sports facilities are lacking. Item (5) indicates that "there are specific and accurate standards for evaluating security performance in sports facilities". Its relative importance was (59.91\%). This item was not statistically significant as there are no specific and accurate standards for evaluating security performance in sports facilities through identifying risk factors. Risk factors include natural risks that may lead to sudden falls or 
cracks of terraces. It also include human risks like over crowdedness either inside the facility, at the doorways or even at exits as this may cause heavy traffic. Risks also include collapse of terraces due to poor designs, fire incidences and other factors. In addition, risks also include attacking players, Refereesor public figures either with or without weapons and explosives.

There are statistically significant differences in favor of those who answered (not available) as $\mathrm{CHI}^{2}$ values were higher than its table value except for items $(4,8,9$ and 10). The most important item was item (9) stating that "there is a crisis department inside each facility". Its relative importance was $(51.8 \%)$. This indicates a major limitation due to the absence of a crisis department inside each facility that work on solving any security problem.

Gameel (2005) indicated that the most significant crises of youth centers in Al-Minia governorate were financial followed by activities then come membership (4).

Item (4) indicates that "experts are employed to develop safety measures inside facilities". Its relative importance was $(50.9 \%)$. This indicates a limitation in safety measures inside sports facilities according to international standards. Item (8) indicates that "equipment and devices are available to face accidents and emergency situations". Its relative importance was $(49.1 \%)$. This indicates that equipment and devices are not available to face accidents and emergency situations. Item (10) indicates that "there are security cameras allowing quick intervention in cases of crises". Its relative importance was $(46.85 \%)$. This indicates that modern technology is not used to secure sports facilities and this imposes several challenges due to the lack of monitoring and control room which plays a major role in monitoring and protecting facility in advance.

Finch et al (2009) agreed with these results as they classified factors affecting facility security into three types: internal (training and culture), external (weather - demographic) and governance (industrial standards - insurance). (10: 13461350).

Huang et al (2011) indicated that establishment standards are specific to each area (urban/rural) and should fulfill the needs of audience. These standards should include: establishing a facility system related to these standards and considering the quality of facilities, audience and numbers of beneficiaries (12: 531-536).

These results indicate that safety measures in sports facilities are established through dedicating enough funds to apply international standards of safety. These standards include: using fire alarm systems, employing security experts, establishing accurate standards for evaluating safety performance, providing audience with necessary information, using security cameras for quick intervention in cases of crises.

Table (10)

Sample opinions about the third axis: nature of crowds' behaviors inside sports facilities $(n=74)$

\begin{tabular}{|c|c|c|c|c|c|c|c|c|c|}
\hline \multirow{2}{*}{ Item } & \multicolumn{2}{|c|}{ Available } & \multicolumn{2}{|c|}{ Somehow available } & \multicolumn{2}{|c|}{ Not available } & \multirow{2}{*}{ Relative weight } & \multirow{2}{*}{ Relative importance } & \multirow{2}{*}{$\mathrm{CHI}^{2}$} \\
\hline & $\mathrm{F}$ & $\%$ & $\mathrm{~F}$ & $\%$ & $\mathrm{~F}$ & $\%$ & & & \\
\hline 1 & 27 & 36.49 & 28 & 37.84 & 19 & 25.68 & 156 & 70.27 & 1.97 \\
\hline 2 & 31 & 41.89 & 13 & 17.57 & 30 & 40.54 & 149 & 67.12 & 8.3 \\
\hline 3 & 21 & 28.38 & 35 & 47.3 & 18 & 24.32 & 151 & 68.02 & 6.67 \\
\hline 4 & 7 & 9.46 & 23 & 31.08 & 44 & 59.46 & 111 & 50 & 27.92 \\
\hline 5 & 5 & 6.76 & 13 & 17.57 & 56 & 75.68 & 97 & 43.69 & 60.99 \\
\hline 6 & 51 & 68.92 & 11 & 14.86 & 12 & 16.22 & 187 & 84.23 & 42.18 \\
\hline 7 & 37 & 50 & 13 & 17.57 & 24 & 32.43 & 161 & 72.52 & 11.7 \\
\hline 8 & 12 & 16.22 & 19 & 25.68 & 43 & 58.11 & 117 & 52.7 & 21.43 \\
\hline 9 & 43 & 58.11 & 13 & 17.57 & 18 & 24.32 & 173 & 77.93 & 20.94 \\
\hline 10 & 39 & 52.7 & 24 & 32.43 & 11 & 14.86 & 176 & 79.28 & 15.92 \\
\hline
\end{tabular}

$\mathrm{CHI}^{2}$ on $\mathrm{P} \leq 0.05=5.99$

Table (10) shows frequencies, percentages, relative weight, relative importance and $\mathrm{CHI}^{2}$ of sample opinions about the third axis: nature of crowds' behaviors inside sports facilities. $\mathrm{CHI}^{2}$ calculated values were higher than its table value (5.99) for all items of this axis. $\mathrm{CHI}^{2}$ values ranged between (60.99) and (1.97). Relative importance ranged between (84.23\%) (Highest value for item 6) and (43.69\%) (Lowest value for item 5).

There are statistically significant differences in favor of those who answered (available) for items (2, 6, 7, 9 and 10) as $\mathrm{CHI}^{2}$ values were higher than its table value. The most important item was (6) stating that "intolerant behavior of the crowds indicates following those who have privates agendas away from sportsmanship" with a relative importance of $(84.23 \%)$. Item (10) indicates that "increased hooliganism needs strict and firm laws to be enforced over clubs and audience". Its relative importance was (79.28\%). Item (9) indicates that "weak and indecisive decisions for deterring intolerant audiences lead to riots and hooliganism in other activities". Its relative importance was (77.93\%). Item (7) indicates that "bad and violent behaviors cause heavy losses to sports facilities". Its relative importance was 
$(72.52 \%)$. Item (2) indicates that "sports facilities have qualified security guards to deals according to audience behavior". Its relative importance was $(67.12 \%)$. This clearly indicates that we should differentiate between regular audience and intolerant audience. Regular audience is not interested in teams, players or Refereesas they are concerned with enjoying good play. On the other hand, intolerant audience are directly interested in all these factors and this leads to their intolerant behaviors.

Allawy et al (1984) indicate that riot is directly related to aggression, violence and intolerance among audience and spectators. This is called audience riot which means a set of behavioral patterns related to emotions of audience under specific conditions. These behavioral patterns are inconsistent with general behavior specified by the society according to its conditions, social and educational standards and other factors (3).

Courney and Carron (1993) indicated that reasons of aggressive behavior include playing at home or away. Some visiting teams seek aggressive behavior and violence more than home teams. This is due to reactions to audience cheers against visitors or deep convection of visitors that they play against intolerant audience (8: 20-27).

There are statistically significant differences in favor of those who answered (somehow available) for item (3) as $\mathrm{CHI}^{2}$ values were higher than its table value except for item (1). The most important item was (1) stating that "facility administration puts signs encouraging sportsmanship and good behavior" with relative importance of $(70.27 \%)$. This item was not significant indicating a limitation in facilities administrations who neglect the importance of spreading sports awareness among audience. Item (3) indicates that "media negatively affects audience feelings". Its relative importance was $(68.02 \%)$. Media adopts perspectives that stimulate audience for riots and violence in sports facilities according to private benefits of some individuals and boards. This increases the gap between clubs and audience and increases crises among audience, especially with the absence of media role in qualifying audience against intolerance. Results of firm law enforcement will not only make audience feel more secure. It will also deter those who may commit crimes as they know that they will be hunted by the police as soon as they commit their crimes.

There are statistically significant differences in favor of those who answered (not available) as $\mathrm{CHI}^{2}$ values were higher than its table value except for items (4, 5 and 9). The most important item was item was (8) stating that "facility administration respond quickly to any undesired behavior of audience". Its relative importance was $(52.7 \%)$. This indicates that elements and tools for monitoring audience and quick intervention to prevent undesired behaviors are not available. Item (4) indicated that "there are strict regulations for preventing riots". Its relative importance was $(50 \%)$. There are limitations in rules and regulations preventing riots in courts. Item (5) indicated that "security measures inside facilities prevent home team fans from directing assaults to visiting team fans". Its relative importance was $(43.69 \%)$. This indicates limitations in securing sports facilities from inside, especially terraces.

According to the researcher's experience, it is clear that Egyptian sport is infected with hatred and intolerance where emotions dominate and rational thinking disappears to the extent that concrete facts cannot change solid beliefs of the intolerant individual or group.

Allawy et al (1984) indicated that fans are very extreme in their rejoicing when winning and in sadness when defeated in addition to continuously justifying their team's defeats. (3).

Myers (1996) indicated that intolerance is an unjustifiable negative trend towards a specific group and each one of its members. It is a pre-judgment and a type of social trends consisting of cognitive, emotional and inclination components (17: 450-461)

Allawy (2004) identifies audience intolerance as "a prejudgment with or against an individual, a group or a topic, that is not based on logic or facts. It makes individuals see or hear what they like to see or hear and stop seeing or hear what they don't like to see or hear". Intolerant persons are inclined to being violent with others, things or even themselves. They are closed-minded and inflexible. They can be easily affected by authority figures or the media. They feel anxiety but they suppress it until they direct it towards those who they are intolerant with $(2: 67,40-45)$.

White (1999) indicated that sports critics should concentrate on negative effects of violence and riots in sport in addition to differentiating between masculine play or assertive behavior and sports aggression in addition to decreasing the importance of winning disregarding the importance of sportsmanship and ethical values (24: 20-25).

As Volkamer (1996) indicated, the researcher thinks that sports violence can be attributed to various reasons including psychological characteristics of sports audience that may lead to violence inside or outside the terraces. Audience behavior as a group is totally different form each individual's behavior as their emotions are unified in one trend forming what is known as "Group Mind" (23: 92-97).

Bull (2001) indicated that causes of aggressive behavior and violence among players are: competition - point differential - physical contact - referees - coaches - league standing outcome of the contest (6: 55-62).

It is noticeable that crowds and fans riot during sports competitions happens inside and outside courts and it may be related to sabotage and destruction of facilities and courts or assaults to others and security guards. Therefore, enough number of security guards should be employed according to the importance of the sports event. In addition, searching the audience for any banned materials should be obligatory. Numbers of audience should be monitored in addition to closing doors to prevent over crowdedness. Audience should be monitored during interacts and deterring procedures 
against hooligans should be swift. Security guards should not leave their positions till all audience exit the court. Joint procedures concerning securing sports facilities include coordination among all bodies concerned with safety measures of sports facilities. These bodies include police forces, firefighters, traffic officers, administrative authorities and concerned sports federations. Safety measures should be consistent with international measures. These results in general indicate that violence among players and audience in addition to facility management my lead to some security implications.

Marsden (1998) indicated that over crowdedness, fire incidences, explosions and collapse of terraces happen every year in sports facilities. These unfortunate incidences lead to many casualties. Therefore, these incidences should be controlled. Reasons for security control over crowds include that the increased number of people inside the same place increase the risk of unexpected incidences. All individuals in the crowd are totally convinced that there is someone who is responsible for their safety. Mass crowds complicate and delay movement. Mass crowds delay communication. Number of casualties increase with the increase of number of crowds (14: 171-175).

Results of this study are consistent with Gameel (2005), Zhang et al (2007), Finch et al (2009), Zhang et al (2009) and Huang et al (2011) in that analyzing current reality of sports facilities is the main road to solve current security problems to reach standards suitable for each individual facility according to the needs of citizens in the surrounding areas. (5) (25) (10) (26) (12).

Shamansouri \& Hashemi (2010) indicated that there are three major factors representing the reasons of sports crises: factors concerning facility management - factor concerning facility structure and social and psychological state of audience - factors concerning media. These factors should be dealt with according to a recommended strategic model for crisis management (18: 79-83).

This study is also consistent with Al-Owainy (2012) and Abu Al-Ainin (2012) in that evaluating facility management helps identifying its objectives and roles in addition to administrative processes that affect security implications in these facilities (4) (1).

It is clear that securing sports facilities prevent security implications. It is very important to identify the responsibilities of security guards in securing such facilities in addition to putting specific plans for such procedures. Securing facilities depends on specific rules and regulations according to the requirements and modern advances in facility structure. Procedures of securing facilities differ in unusual situations compared to regular procedures of regular situations. Some procedures are related to communication while others concern transportation. Finally, safety procedures depend on the efficiency of security guards in initiating these procedures. Therefore, security specialists should know well basics and rules of securing facilities in addition to risks concerning these procedures.

\section{Conclusions:}

In the light of this research results, the researcher concludes the following:

Concerning the nature of sports facility structure from a security perspective:

- There is an alternative power supply to be used in need.

- There is an emergency care and first-aid unit inside the facility

- $\quad$ Roads leading to the facility can be secured easily

- $\quad$ Sports facilities are not far from heavy traffic

- $\quad$ Signs for services provided inside the facility are not enough

- There are no extra emergency exits

- There is not enough room to enter or exit the facility

- Doors are not opened onwards or outwards as needed

- Facility design is not consistent with security measures for human and material capabilities

- The sports facility is inside the residential area

- Wideness of doors is not consistent with numbers of beneficiaries.

Concerning safety measures in sports facilities:

- Separate seats are dedicated for each team's fans.

- Audiences do not have enough information about security and safety services inside the facility.

- Entrances and exits are not located according to terraces' capacity

- Sports facilities need fire alarms according to safety measures

- Funds are not enough for applying maximum security and safety measures inside facilities

- Sports facilities need accurate criteria for evaluating safety and security performance.

- There is no crises department inside facilities.

- Experts are not employed to improve safety and security measures inside facilities.

- Equipment and devices for facing emergency situations and crises are lacking.

- There is not enough security cameras swift intervention in cases of crises.

Concerning nature of crowds' behaviors inside sports facilities:

- Intolerant behavior of crowds indicates that they follow others who have other interests than sports behavior.

- Increased crowds riots need for firm laws to be applied on clubs and fans.

- Resilient and indecisive decisions do not intolerant crowds and increase violence in other sports activities.

- Violent and bad behavior of crowds leads to mass losses for facilities.

- $\quad$ Security guards qualified for dealing with crowds play a minor and unclear role. 
- Signs for increasing crowds' awareness with the importance sportsmanship and good behavior inside facilities are lacking.

- Media negatively stimulates crowds' emotions.

- Facility administrators do not respond quickly to resentful crowds' behaviors.

- Rules and regulations of sports facilities are not firm enough to prevent riots.

- Security measures inside the facility do not prevent assaults targeting fans of the opponent team .

\section{Recommendations:}

In the light of participants' responds to the questionnaire, the researcher recommends the following:

1. There should be maps and guiding signs indicating entrances and exits of the facility in cases of matches with heavy attendance.

2. There should be preventive measures for transporting players and technical and managerial staff into safety zones.

3. There should be procedures for controlling dangerous tools audience might take with them into the facility.

4. Facility design should consider international standards of safety and security for human and material capabilities .

5. Holding training courses about crises management and how to deal with them for administrative and operating staff of facilities.

6. Coordinating with traffic police to control the path and flow of transportation from and to facilities .

7. There should be entrances and exits safe enough for audiences.

8. There should be emergency exits for athletes, coaches, referees and audiences.

9. There should be a fully equipped firefighting system .

10. Experts with various specialties should be consulted about places of establishing sports facilities, equipment needed for them and mechanisms of crises management.

11. There should be security cameras for swift intervention in cases of crises.

12. Media should play a vital role in increasing audiences' awareness instead of escalating or creating crises with athletes, clubs or fans

13. Timeframe for security services needed for events should include before during and after events while geographic zone should include securing arrival and departure of all team members and fans.

14. Increasing the awareness of administrative staff of facilities about the risks of not applying safety and security measures.

15. There should be a mechanism for cooperation between authorities and sports bodies in the field of safety and security measures.

\section{References:}

1. Abu Al-Ainin, Nagla Fawzy, Evaluating sports facilities of higher education in new cities in the light of quality standards. PhD thesis, Faculty of Physical Education for Women - Helwan University, 2012 (in Arabic)

2. Allawy, Mohamed, Psychology of aggression and violence in sport, $2^{\text {nd }}$ ED. Dar Al-Ketab Press - Cairo, 2004 (in Arabic)

3. Allawy, Mohamed et al, Crowds' riot in Egyptian soccer fields. International conference of Sport for All, Faculty of Physical Education for Men -Helwan University, 1984 (in Arabic)

4. Al-Owainy, Ibrahim Abd El-Sattar ,Evaluating sports facilities of Minofia University. PhD thesis, Faculty of Physical Education for Men - Banha University, 2012 (in Arabic)

5. Gameel, Abd El-Hakeem Mohamed, Sports cises and its relation to decision making ability for administrative leaders in youth centers of Al-Minia Governorate. Master thesis, Faculty of Physical Education- Al-Minia University, 2005 (in Arabic)

6. Bull, S., Sport psychology, $2^{\text {nd }}$ ed. The Crowood Press, 2001,pp: 55-62.

7. Coalter, F., Sports Clubs, Social Capital and Social Regeneration: 'ill-defined interventions with hard to follow outcomes'?. Sport in society, 10(4), 2007 , pp: 537-559.

8. Courney, K. and Carron, A The home advantage in sport competition. JSEP, 14, 1993, pp :20-27.

9. Decker, R.Key elements of risk management approach, United Indicates General Accounting Office. (2001), www.gao.gov/new.ite $\mathrm{ms} / \mathrm{do} 2150 \mathrm{t}$

10. Finch, Caroline, et al."The safety policies and practices of community multi-purpose recreation facilities." Safety science $47.10,2009$,pp: 1346-1350.

11. Forsdic, S.Cultural complexity in British Stadium safety industry. Butterworth-Hein mum, 1997

12. Huang, Ming Hua, Xin Wu, and Xiao Nan Shi."A Study of the Suitability Standards of Sports Facilities in Counties Governed by Ankang City." Applied Mechanics and Materials 99 ,2011,pp: 531-534.

13. John Baldoi, Leadership and decision Making , Unpublished Lectures, Southern California University .2000 .

14. Marsden A. Training railway operating staff to understand and manage passenger and crowd behavior. Industrial and commercial training, Vol.30, No. 5, 1998, PP: 171-175.

15. Mattew J. Best practices for game day security, Sports Journal, Vol.6, 4, 2003 
16. Ministry of Youth and Sport (Egypt)Rules and regulations for operating sports facilities and its attachments, Ministry of Youth and Sport Press 2007 (in Arabic)

17. Myers, D. Social psychology $5^{\text {th }}$ ed. McGraw-Hill, Inc., 1996. Pp: $450-461$.

18. Shamansouri, E., \& Hashemi-Minabad, H. A. S. A. N. Causes of sport crises, ways of their elimination and a crisis-management strategic model. Studies in Physical Culture \& Tourism, 17(1) ,2010, pp79-83.

19. Spiro, G. et al, Crowd management past and contemporary issues. The Sport Journal, vol.9, 2 .2005.

20. Stacey Hall, Effective security Management of University Sports Venues. Sports Journal , Vol. 9, 4. ,2006.

21. Taylor, R. \& Plumely E. Question session where do we go from here/ in sports stadium after Hillsborough, paper presented at a sports council, 1998, P: 102

22. Tenenbaum, G. \& Stewart R. Aggression and violence in sport, 1997, www.issponline.org

23. Volkamer, M. Aggression in relation to sport. The Athletic Institute, 1996, pp:92-94 .

24. White, G. Media and violence. The Growood Press, 1999, pp: 20-25.

25. Zhang, Qingsong, et al."A stranded-crowd model (SCM) for performance-based design of stadium egress." Building and environment 42.7 ,2007, pp: 2630-2636.

26. Zhang, Qingsong, Guomin Zhao, and Jinlan Liu, Performance-based design for large crowd venue control using a multi-agent model, Tsinghua Science \& Technology $14.3,2009, \quad$ pp: $352-359$. 
